\title{
Splitting leagues: promotion and demotion in contribution-based regrouping experiments
}

\author{
Susana Cabrera • Enrique Fatás • \\ Juan A. Lacomba • Tibor Neugebauer
}

Received: 7 March 2011 / Accepted: 26 September 2012 / Published online: 17 November 2012

(C) Economic Science Association 2012

\begin{abstract}
The paper reports an experimental study on a promotion-demotion mechanism to mitigate the free-rider problem in a voluntary contribution setting. The mechanism hierarchically splits a group in two; we refer to one subgroup as the Major league and to the other as the minor league. The most cooperative subject of the minor league is switched with the least cooperative subject in the Major league. The results reveal a significant increase of cooperation levels in both leagues relative to the standard voluntary contribution mechanism. We argue that a lack of sequentially-rational beliefs about continuation payoffs in Major and minor leagues leads to higher equi-
\end{abstract}

\footnotetext{
We thank Jacob Goeree, two anonymous referees and seminar participants at Tucson and Magdeburg for helpful comments. Financial support from the Spanish Ministry of Education and Science (ECO2010-20584), Generalitat Valenciana (PROMETEO/2009/068) and Junta de Andalucíia (P07-SEJ-3261) is gratefully acknowledged. An earlier title of the paper has been "Vertically Splitting a Firm: Promotion and Relegation in a Team Production Experiment".
}

Electronic supplementary material The online version of this article

(doi:10.1007/s10683-012-9346-4) contains supplementary material, which is available to authorized users.

S. Cabrera

University of Málaga, Málaga, Spain

e-mail: yeto@uma.es

E. Fatás

University of East Anglia, Norwich, UK

e-mail: fatas@uv.es

J.A. Lacomba ( $\varangle)$

GLOBE, University of Granada, Granada, Spain

e-mail: jlacomba@ugr.es

T. Neugebauer

LSF, University of Luxembourg, Luxembourg, Luxembourg

e-mail: Tibor.Neugebauer@uni.lu 
librium contributions. The data suggest beyond that, the promotion-demotion mechanism regroups subjects deliberately according to their cooperativeness.

Keywords Experiment · Group incentives · Organization design

JEL Classification $\mathrm{C} 92 \cdot \mathrm{H} 41 \cdot \mathrm{J} 33 \cdot \mathrm{J} 4$

\section{Introduction}

Numerous papers have shown that endogenous grouping, and contribution-based grouping raises contribution levels (Erhard and Keser 1999; Coricelli et al. 2004; Page et al. 2005; Gächter and Thöni 2005; Burlando and Guala 2005; Gunnthorsdottir et al. 2007; Ones and Putterman 2007; Ahn et al. 2008, 2009; Charness and Yang 2010; Charness et al. 2011). Our study confirms once more that contribution-based grouping raises efficiency. Furthermore, we show that contribution-based grouping works even with a design where the contribution-based movement of group members is limited to a few players. Recently, Gunnthorsdottir et al. (2010a, 2010b) have developed and tested a formal model of contribution-based grouping. Their work suggests that, in some cases at least, the observed rise in contribution can be accounted for by a non-obvious equilibrium. Gunnthorsdottir et al.'s approach however is simultaneous; it requires that contribution decisions, grouping and earnings computations all occur in the same round. There is thus no room for reputation effects or hypothesis about the types of other players or group members. Other researchers have sketched Bayesian Nash Equilibria approaches to endogenous group formation, which incorporate monetary as well as non-monetary incentives, and which could incorporate lags, reputation effects, and individual estimates of others' types. Most relevant here in this regard is probably Ones and Putterman's (2007) paper. They design a public goods experiment with targeted punishment opportunities and confirm subject heterogeneity. They also find that differences in the inclination to cooperate have persistence and that differences in group outcomes can be predicted by knowing the types of individuals who compose those groups. We contribute to the growing speculation about BNE approaches and type ecologies to endogenous grouping by sketching our own model in the context of restricted endogenous grouping.

The experimental design that we introduce employs a promotion-demotion (or leagues) scheme as is frequently used in the structural organization of modern societies: ${ }^{1}$ a cohort is hierarchically split into two equally-sized divisions, to which we refer to as the Major and the minor league. Although our experimental design and in particular the Leagues treatment involves a neutral framing, the division that wins the between-team competition in the first repetition is positioned as the Major league. For every following repetition, the most cooperative subject in the minor league promotes to the Major league, and the least cooperative subject in the Major league demotes to the minor league. Our leagues scheme allows subjects within

\footnotetext{
${ }^{1}$ Some studies have investigated the use of promotions and demotions to provide incentives in work or sports environments (e.g., Lazear 1992; Kräkel 2006; and Belzil and Bognanno 2008).
} 
the limitations of this approach to endogenously regroup depending on their willingness to cooperate. While such a group self-formation possibility does not affect the perfect Bayesian-Nash equilibrium of the game per se, positive (non-perfect) Bayesian-Nash equilibrium contributions loom. By way of example we show the existence of such equilibria and thus conjecture a positive effect on cooperation. In particular, we argue, that players myopically account for two sources of revenue; on one hand the payoff in the current repetition and on the other hand the continuation payoff according to the prospect of their group affiliation in the next repetition. Given the possibility that beliefs about the behavior of players in the other league are not sequentially rational, we show that positive-contribution equilibriumlevels can arise. It should be noted that we make no assumptions regarding the irrationality of player types or about other-regarding preferences as suggested in related research. If, for instance, conditional-cooperative players are present or if rational players have beliefs of the presence of such players, perfect Bayesian-Nash equilibria exist that involve positive contributions (Ahn et al. 2003; Page et al. 2005; Ones and Putterman 2007; see also Proposition 2 in Levati and Neugebauer 2004). ${ }^{2}$

In line with our conjectures, we find that the contribution levels of the Major league exceed those of the minor league, which again significantly exceed those of the standard voluntary contribution mechanism. We observe that subjects sort themselves into groups according to their cooperativeness; the more cooperative subjects participate in the Major league and thus distinguish themselves from the less cooperative subjects who stay in the minor league. Two further control treatments show that the efficiency-enhancing effect is weakened if initial conditions are changed, ceteris paribus. If, on one hand, the more cooperative division is equally likely selected as the Major or minor league, initial contribution levels drop to levels of the voluntary contribution mechanism. Likewise, on the other hand, if feedback information is always given about both minor and Major leagues' contributions thus largely removing the subsistence of non-sequential rational beliefs, cooperation levels are reduced initially, too. Since contributions converge with repetition on the levels of the Leagues treatment, however, we assume conditional cooperation and adaptation of beliefs (e.g., Neugebauer et al. 2009) to past continuation payoff differentials as yet another source for increased contributions besides non-sequential rationality.

The paper is organized as follows. The following section describes the design and alludes to the theoretical predictions. In the third section we report on the data of our study. The fourth section presents more data on design variations. Finally, the fifth section provides some concluding remarks.

\section{Experimental design \& theoretical considerations}

The baseline treatment-the VCM The experimental design employs a repeated standard voluntary contribution mechanism (hereafter VCM) in a partner's setting. Cooperation and free-riding are framed as contributions to a group project and contributions to an individual project, respectively. Subjects participated in groups of

\footnotetext{
${ }^{2}$ In Page et al. (2005), reputation-building creates the rationale for beliefs in a positive continuation-payoff.
} 
four and were endowed with 50 Eurocent per round, which they privately divided between the "group project" and the "individual project". The per-capita-return of a unit of contribution to the group project was one half; each two Eurocent contributed in group interest generated a payoff of one Eurocent for every group member. The individual project returned contributions one to one. More formally, the individual payoff function writes as follows:

$$
\pi_{i}\left(x_{i}, x_{-i}\right)=50-x_{i}+\left(x_{i}+x_{-i}\right) / 2
$$

where $x_{i} \in[0 ; 50]$ denotes individual $i$ 's contribution to the group project, $i=$ $\{1,2,3,4\}$, and $x_{-i}$ denotes the contribution of the other players. The individual maximizes her payoff by choosing $x_{i}=0$, while the group's payoff is maximized if every individual chooses $x_{i}=50$; hence, individual rationality pits against collective rationality. By backward induction the result of collective free-riding extends to the finitely repeated game. As extensive experimental research on voluntary contribution mechanism has revealed, neither full contribution nor collective free-riding are perfectly supported in the laboratory. ${ }^{3}$

The leagues treatment In the Leagues treatment, each independent observation involved eight subjects initially assigned to two groups of four with equal probability. The two groups were named "Group 1" (the Major league) and "Group 2" (the minor league) according to the group's contribution in the first round of the experiment; the group that had contributed more [less] in the first round was positioned as the Major [minor] league. ${ }^{4}$

It has to be noted that the labels "Group 1" and "Group 2" were assigned according only to the groups' contributions of the first round but they were maintained for the remaining rounds regardless of groups' future contributions. After each round, including the first one, the individual who had submitted the highest contribution to the group project in the minor league moved (promoted) to participate in the Major league in the following round; and the individual who submitted the lowest contribution to the group project in the Major league moved (demoted) to participate in the minor league in the following round. Ties were resolved randomly.

The payoff function of individuals from both, the minor league and the Major league obeys to Eq. (1); promoting or relegating subjects are paid according to the league to which they submitted their contribution. For identical contributions, the payoffs in the Major league would thus be identical to both, the payoffs in the minor league and the payoffs in the VCM. In principle, a subject in the Major league has therefore no different incentives (monetary or other) to make a contribution than subjects in the other conditions; free-riding is the dominant strategy for individual behavior in the one-shot game and is the unique equilibrium strategy in the finitely repeated game. Since the partial equilibrium in the Major league involves collective free-riding, no subject in the minor league has any incentive to promote to the Major

\footnotetext{
${ }^{3}$ Two stylized facts are that subjects contribute between $40 \%$ and $60 \%$ of their endowment to the group project in the first round of the finitely repeated game and that contributions decline in the sequel (surveys are provided in Hey 1991; Davis and Holt 1993; Ledyard 1995; and Keser 2002).

${ }^{4}$ This initial group-assignment rule was common information to participants.
} 
league. Hence, both leagues produce zero contribution levels in the unique equilibrium. Under the assumption of identical players we thus can write down the following comparative hypothesis.

Hypothesis 1 Contribution levels are treatment-independent; the VCM, the Major league and minor league involve zero contributions.

As a matter of fact, hypothesis 1 is the standard game theoretic prediction if all beliefs are sequentially rational but we are not completely intrigued by it. In our opinion, it is rather likely that players in the game believe that the Major league produces higher contributions than the minor league. Let us elaborate on this idea a bit further. For the ease of the presentation, assume that players are myopic payoff maximizers who only look one round ahead and expect a continuation payoff by affiliating to the Major or minor league in the next round. Let the continuation payoff be denoted by $\alpha_{M i}$ and $\alpha_{m i}$, respectively. Hence, players perceive the payoff received in one round of the game as two payoffs, the payoff from the current round and the continuation payoff according to their affiliation of the following round. This assumption seems to be unadventurous since present contributions only determine the affiliation of subjects in the next round. More formally, given player $i$ is in the Major league (M), her perceived payoff is as follows.

$$
\begin{aligned}
& \tilde{\pi}_{i}\left(x_{i}, x_{-i} ; \alpha_{M i}, \alpha_{m i}\right) \\
& \quad=\pi_{i}\left(x_{i}, x_{-i}\right)+ \begin{cases}\alpha_{M i} & \text { if } x_{i, M}>\min x_{j, M}, j \neq i \\
\left(\alpha_{M i}\left(n_{M}-1\right)+\alpha_{m i}\right) / n_{M} & \text { if } x_{i, M}=\min x_{j, M}, j \neq i \\
\alpha_{m i} & \text { if } x_{i, M}<\min x_{j, M}, j \neq i\end{cases}
\end{aligned}
$$

where $\pi_{i}\left(x_{i}, x_{-i}\right)$ is $i$ 's payoff according to (1) and $n_{M}$ denotes the number of tied minimum contributions in the Major league. On the other hand, given $i$ is in the minor league in the current round her perceived payoff is described as follows.

$$
\begin{aligned}
& \tilde{\pi}_{i}\left(x_{i}, x_{-i} ; \alpha_{M i}, \alpha_{m i}\right) \\
& \quad=\pi_{i}\left(x_{i} ; x_{-i}\right)+ \begin{cases}\alpha_{M i} & \text { if } x_{i, m}>\max x_{j, m}, j \neq i \\
\left(\alpha_{m i}\left(n_{m}-1\right)+\alpha_{M i}\right) / n_{m} & \text { if } x_{i, m}=\max x_{j, m}, j \neq i \\
\alpha_{m i} & \text { if } x_{i, m}<\max x_{j, m}, j \neq i\end{cases}
\end{aligned}
$$

where $n_{m}$ denotes the number of tied maximum contributions in the minor league.

The beliefs about the continuation-payoff differential for affiliating with the Major and the minor league $\left(\alpha_{M i}-\alpha_{m i}\right)$ determine the Nash-equilibrium contributions. ${ }^{5}$

\footnotetext{
${ }^{5}$ The differential is bounded between $0 \leq\left(\alpha_{M i}-\alpha_{m i}\right) \leq 75$ since the continuation payoffs depend on the others' contributions. At best, for the player in the Major league, the others contribute everything and, at worst, for the player in the minor league, the others contribute nothing. Thus, the advantage of being in the Major league in the next round can not exceed 75. On the other hand, if players do not care about their future location the expected advantage of being in the Major league is zero.
} 
The unique equilibrium allocation for which beliefs are accurate is the one proposed by Hypothesis 1, and involves zero continuation payoffs. To see that the symmetric zero-contribution equilibrium is the unique perfect Bayesian-Nash equilibrium of the game, consider any symmetric contribution profile in the minor league and assume that being in the Major league is advantageous $\left(\alpha_{M i}-\alpha_{m i}\right)>0 .{ }^{6}$ Since the probability of being promoted is $1 / n_{m}=\frac{1}{4}$, the increase of one's contribution by less than $3 / 4 \times\left(\alpha_{M i}-\alpha_{m i}\right)$ is beneficial, given that the deviant is being promoted with probability one. ${ }^{7}$ Only on the boundary, if all players in both leagues contribute their endowment, contributions cannot be increased further. But if all players contribute their endowment being in the Major league cannot be advantageous anymore $\left(\alpha_{M i}-\alpha_{m i}\right)=0$, and players in the Major league would then do better by contributing nothing. Hence, if and only if contributions in both leagues are zero, such that $\left(\alpha_{M i}-\alpha_{m i}\right)=0$, beliefs are sequentially rational; thus, zero contribution results in the unique perfect Bayesian-Nash equilibrium.

However, we know from previous experimental studies that beliefs about the contributions of the others' usually vary among human subjects and differ from the contributions of the others (e.g., Fischbacher and Gächter 2010; Croson 2007; Neugebauer et al. 2009). ${ }^{8}$ If we allow players to hold non-sequentially rational beliefs, (non-perfect) Bayesian-Nash contribution profiles exist which support positive average contributions in both leagues with greater average contributions in the Major league. Assume, e.g., that two players in the minor league believe that $\alpha_{M j}=\alpha_{m j}=50$ and contribute nothing while all other players in the minor and Major league believe that $\alpha_{M i}=75$ and $\alpha_{m i}=25$; while the former players do best by contributing nothing given their beliefs, all other players do best by contributing their endowment. $^{9}$

A subject believing that others' contributions in the Major league are larger than in the minor league generally has incentives to increase her contribution in order to be promoted to the Major league or to avoid to be demoted to the minor league. Thus, since for various beliefs the contributions in the minor and the Major league may be strictly positive. Under the assumption that non-perfect Bayesian-Nash equilibria that involve positive contributions are selected with positive probability, the following hypothesis can be written down.

Hypothesis 2 Contribution levels are likely to be higher in the Major league than in the minor league and in the minor league higher than in the VCM.

\footnotetext{
${ }^{6}$ An asymmetric contribution profile cannot be part of a perfect Bayesian-Nash equilibrium since some players can always do better by lowering their contributions.

${ }^{7}$ Note that the line of reasoning is the same for mixed strategies as the increment in the probability corresponds to a higher probability of being promoted and a higher expected payoff.

${ }^{8}$ There is more experimental evidence of heterogeneous, non-sequentially-rational beliefs; e.g., see the literature on the beauty-contest experiment (Nagel 1995).

${ }^{9}$ It is noteworthy that this example allows time-consistent beliefs in the repeated setting since the two players who hold wrong beliefs about the Major league have no opportunity to update them given that they are affiliated to the minor league always.
} 
In the literature on voluntary contributions it has been observed that beliefs about others' contributions are positively correlated with one's own contribution level (see e.g., Keser and van Winden 2000; Fischbacher et al. 2001; Brandts and Schram 2001; Croson 2007; Fischbacher and Gächter 2010; and Neugebauer et al. 2009). Due to the positive correlation, one possible implication of Hypothesis 2 could be that the more cooperative players regroup in the Major league if they expect that the more cooperative players will participate in that league. In fact and while not theoretically addressed, ${ }^{10}$ this possible implication is another research question addressed in the present paper.

Procedures The experimental design was implemented in a partner's setting using the software zTree (Fischbacher 2007). The sessions were run at the laboratory for experimental research LINEEX at the University of Valencia. The distinguishing feature in the experimental setting of the VCM was the feedback information. Subjects received feedback information on individual contributions ordered from the maximum to the minimum; however, individual contributions could not be traced to the contributor. This information (and private information on round payoffs) was displayed in a table for all previous rounds during and after each round on the subject's computer screen. In the Leagues treatment, subjects received additional information on the "Group" ( 1 or 2$)$ to which they contributed and they were informed when they moved from one league to the other; members in the major league received no information on the contributions in the minor league and vice versa. Before the experiment, subjects completed a quiz to make sure they had fully understood the logic of the game (see the Appendix for the questionnaire).

\section{Experimental results}

The VCM baseline treatment involves 24 subjects, i.e., 6 independent groups of 4 subjects. The Leagues treatment involved 80 subjects, i.e., 10 independent groups of 8 subjects. By participating to the experiment a subject earned on average 16 Euro. The experiment was completed within an hour.

Treatment effect Table 1 represents the average contributions toward group interest in each round of the experiment. The contributions in the minor and the Major leagues are recorded as well as the treatment averages. Test results are presented in the last two rows of the table. Based on these results, we write down our first observation which supports Hypothesis 2 and rejects Hypothesis 1.

\section{Observation 1}

(a) Contributions in the minor league are significantly larger than in the VCM for the whole experiment and for each round.

\footnotetext{
${ }^{10}$ We theoretically discuss the impact of sequential rationality of strictly self-interested players in this paper only. A more general behavioral model would have to take account of the fact that people are heterogeneous with regards to their homegrown willingness-to-cooperate and their beliefs about others.
} 
Table 1 Average contributions to the group project (Maximum Possible = 200)

\begin{tabular}{|c|c|c|c|c|c|c|c|c|c|c|c|}
\hline & \multicolumn{10}{|l|}{ Round } & \multirow[t]{2}{*}{ Overal } \\
\hline & 1 & 2 & 3 & 4 & 5 & 6 & 7 & 8 & 9 & 10 & \\
\hline VCM & 81 & 79 & 78 & 82 & 83 & 63 & 50 & 47 & 39 & 36 & 64 \\
\hline League & 128 & 138 & 137 & 137 & 127 & 118 & 128 & 121 & 103 & 74 & 121 \\
\hline Major L. & 152 & 162 & 161 & 153 & 144 & 131 & 146 & 131 & 129 & 82 & 139 \\
\hline Minor L. & 104 & 115 & 114 & 121 & 111 & 105 & 109 & 111 & 77 & 66 & 103 \\
\hline \multicolumn{12}{|l|}{ Test results: } \\
\hline \multicolumn{11}{|l|}{ Minor L. ${ }^{\mathrm{a}}$} & 0.011 \\
\hline \multicolumn{12}{|c|}{ Major L. vs. } \\
\hline Minor L. ${ }^{b}$ & 0.003 & 0.003 & 0.008 & 0.063 & 0.018 & 0.077 & 0.026 & 0.030 & 0.003 & 0.101 & 0.003 \\
\hline
\end{tabular}

${ }^{\text {a }} p$-value of the one-tailed Mann-Whitney test (six observations VCM; 10 observations minor league)

${ }^{\mathrm{b}} p$-value of the one-tailed Wilcoxon signed-ranks test (10 observations)

(b) Contributions in the Major league are significantly larger than in the minor league for the whole experiment and for all but the last round.

\section{Support}

As recorded in the second column of the table, the first round average contribution in group interest was 81 Eurocent in the VCM (about $40 \%$ of the endowment) and 128 Eurocent in the Leagues treatment (about $64 \%$ of the endowment); 152 Eurocent in the Major league and 104 Eurocent in the minor league. According to the MannWhitney test, the results of which are recorded in the second last row of Table 1, the contributions in the minor league were significantly greater than in the VCM; the exact $p$-value being 0.021 for the first round. The last row reports the outcomes of the Wilcoxon signed-ranks test on the within-sample differences between the minor and the Major league. By definition we have that the contributions in each Major league cannot be smaller than in the minor league in the first round. However, for completeness we report the resulting asymptotic $p$-value 0.003 for the first round. The test results reported in the following columns confirm Observation 1 at the $10 \%$ significance level. Overall, the average group-contributions were 103 Eurocent in the minor league and 139 Eurocent in the Major league. The data thus indicates that in the experiment real incentives existed to be promoted to and to stay in the Major league.

Continuation-payoff estimate Since subjects cannot expect a further interaction beyond round 10, the expected continuation payoff in that round of the game is zero. Therefore, it seems not surprising that the corresponding difference between the contributions in the Major and the minor league is not significant in that round as recorded in Table 1. To estimate the expected continuation-payoff for the other nine rounds we must make assumptions about players' beliefs. For simplicity let us assume that subjects expect the others to exert the same effort in one round as in the 
previous one. ${ }^{11}$ Thus, a player who stays in the Major [minor] league for two subsequent rounds is assumed to expect a Major [minor] league continuation payoff equal to the sum of present contributions of the other two staying members and of the contributor that is going to enter the league from the minor [Major] league in the following round. If the player moves from the Major [minor] league to the minor [Major] league, because her contribution is the smallest [largest] one, we compute her expected continuation payoff by considering that she would stay in the league and instead of her the player who submitted the second smallest [largest] contribution would leave. Finally, the expected continuation payoff from the minor [Major] league of a Major [minor] league player is assumed to be the repetition of the contributions from the staying members in the minor [Major] league. The thus estimated average expected continuation payoff over the first nine rounds is $\hat{\alpha}_{M}=62\left[\hat{\alpha}_{M}=31\right]$ for the Major [minor] league. ${ }^{12}$

Regrouping effect Despite the difference in the continuation payoff between leagues, the individual payoff is not increasing in the frequency of playing the Major league. The average round-payoff of the four subjects who stayed most frequently in the Major league is $0.80 €$, while the average payoff of the other four subjects who stayed most frequently in the minor league is $0.81 €$. The payoffs of these groups are not significantly different, ${ }^{13}$ thus proposing a "law of one price" in terms of expected payoff. Figure 1 illustrates the relationship between participation in the Major league and the round payoff. According to this chart, subjects who participated only once in the Major league achieved the highest average payoff. ${ }^{14}$

We observe that some subjects moved regularly between the leagues, submitting high contributions in the minor league and almost free-riding in the Major league. Given the additional incentives to collaboration of both cooperators and free-riders to get into the team with more cooperative types the existence of such "arbitrageurial" behavior might not be surprising. 15 The aforementioned "law of one price" in terms of average payoff might have succeeded due to the behavior of these subjects.

\footnotetext{
${ }^{11}$ Note that players are assumed to anticipate the others' contributions as they form their expectations about the continuation payoff at a time, when they have not observed the others' contributions. The assumption that experimental subjects actually form their expectations based on these anticipated contributions is, admittedly, quite demanding. Yet, it seems less demanding than alternative assumptions as, for instance, perfect foresight. Under the perfect-foresight assumption, one arguably biased estimate of the continuation-payoff differential between the leagues would be the difference of the average contributions in the two leagues during the last nine rounds (see Table 1) which is 34 Eurocents.

${ }^{12}$ We reach at a very similar estimation, i.e., $\hat{\alpha}_{M}=62\left[\hat{\alpha}_{M}=32\right]$, if we neglect the assumed expectations of the subjects who are moving from one league to the other.

${ }^{13}$ The $p$-value of the two-tailed Wilcoxon signed ranks test is 0.767 .

${ }^{14}$ Compared to the VCM treatment, the payoffs in the Leagues treatment were significantly greater. Only two of the eighty participants in the Leagues treatment ended up earning less than the average round-payoff of $0.66 €$ the most cooperative group in the VCM achieved. Similarly, only seven subjects of the eighty participants in the Leagues treatment contributed less than the average contribution in the VCM which was $32 \%$ of the endowment (as in the scaling of Fig. 1).

${ }^{15}$ With reference to the behavior of demoted and promoted subjects, we observe that $61 \%$ of the demoted subjects increased their contributions and $63 \%$ of the promoted subjects decreased their contributions in the following round, and $23 \%$ and $24 \%$ did not change their contribution, respectively.
} 
Figure 1 reports also the frequency-distribution of participants in the Major league, e.g., two of the eighty subjects $(2.5 \%)$ participated exactly once in the Major league. If all subjects contributed the same amount, as suggested by the perfect BayesianNash equilibrium, they would be expected to participate five times in the Major league and five times in the minor league. In relation to this suggestion, we state the second main observation resulting from our data analysis.

\section{Observation 2}

Subjects self-sort according to their willingness to cooperate; i.e., the frequency of Major league participation is positively correlated with contribution levels.

\section{Support}

Assuming a random allocation of subjects to leagues, only one in one thousand subjects would be expected to participate zero times or ten times in the Major league. Yet, as shown in Fig. 1, nine of the 80 subjects (11.25\%) participate never and seven subjects $(8.75 \%)$ participate always in the Major league. In fact, the realized distribution looks rather uniform across all possible participation-frequencies. From this observed distribution, it already follows that contributions are not equal across subjects, but that subjects who participate more frequently in the Major league are also those who are more cooperative. The average contribution of the four subjects who participated most frequently in the Major league of their group is 1.5 times the contribution of the remaining four subjects, in money terms a contribution of 0.36 Euro versus 0.24 Euro per round. The difference in contribution levels between these subgroups is positive for each of the 10 independent groups of the Leagues treatment. The likelihood that this extreme result is due to chance is 0.001 . Also, if we order the contributions according to the frequency of Major league participation in each group, we find that contributions and Major league participation are significantly correlated. According to the Page test of ordered alternatives the probability of the observed correlation or an extremer one is 0.000 . Figure 1 illustrates this positive correlation

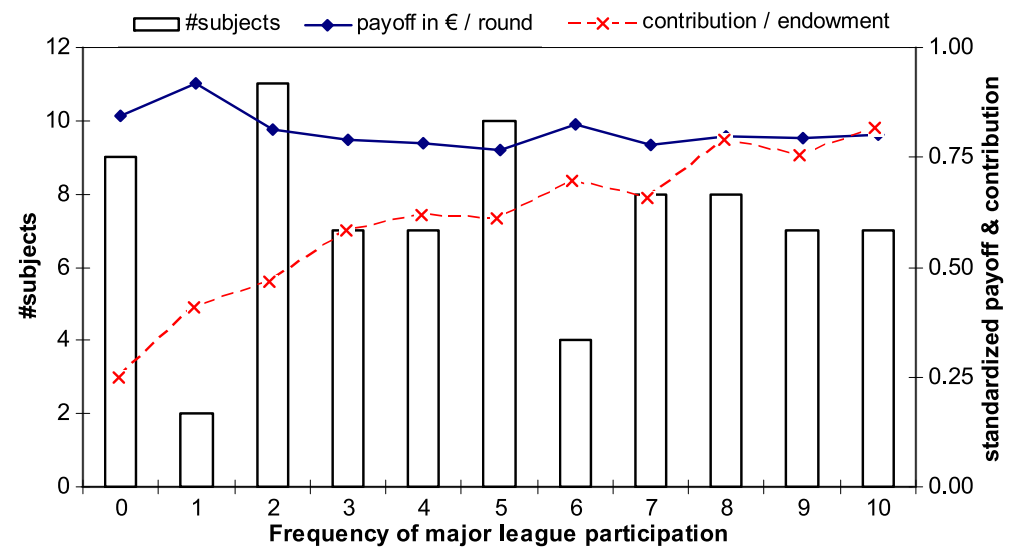

Fig. 1 Average payoff (in Euro), contribution (relative to endowment) and number of subjects by frequency of Major league participation 


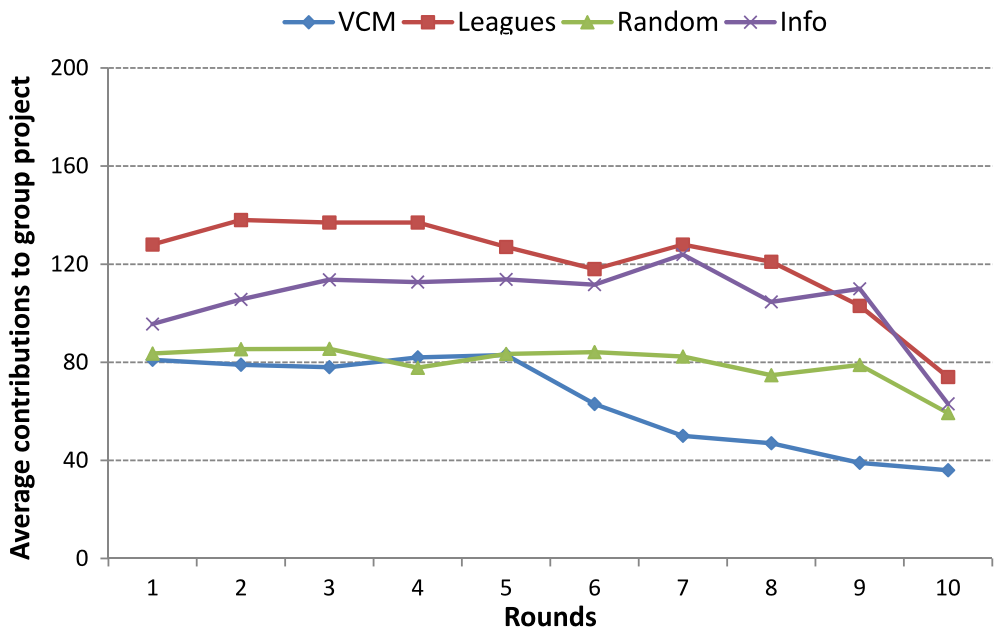

Fig. 2 Average contributions to group project

as the average contribution increases from 12.5 Eurocent, i.e., 0.250 of the endowment, for the nine subjects who participated never in the Major league to 41 Eurocent ( 0.82 of the endowment) for the seven subjects who participated always. Although the forced promotion-demotion mechanism precludes a perfect self-selection of more cooperative subjects, ${ }^{16}$ Observation 2 shows that the incentives of the experimental design were sufficient to instigate a deliberate group-formation process. The result shows, yet, that a self-selection of more cooperative subjects in the Major league may be achieved on a voluntary basis by simply providing an appropriate organizational structure. In our experiment, affiliation with any league exclusively depends on subjects' decisions.

Repetition effect Although contributions are larger in the Leagues treatment than in the VCM, Fig. 2 suggests that contributions may decline across rounds of the experiment in both treatments. To test the significance of the contribution-decline, we run a random-effects regression including a treatment variable which we interact on the intercept and on the slope. The treatment variable, $L_{i}$, takes the value one if $i$ is a subject in the Leagues experiment and zero otherwise. The regression results which are shown in the left column of Table 2 confirm that the decline is significant for both treatments. Though the decline is less pronounced in the Leagues treatment than in the VCM treatment, the slopes are not significantly different from each other.

Since we observe a significant decline of the contributions in the Leagues treatment, an analysis of the dynamics suggests itself. As the recent literature on voluntary contributions has insinuated, the downward spiral of contributions may be caused by selfish-biased conditional cooperation and the successive adaptation of beliefs (Neugebauer et al. 2009). Therefore, we estimate the correlation of contributions

\footnotetext{
${ }^{16}$ For instance, if all four players in the Major league contribute all their endowment and those in the minor league contributed nothing, one of the high contributors will be demoted and one of the defectors will be promoted.
} 
Table 2 Panel data regression Individual contribution $(0 ; 50)$

\begin{tabular}{lll}
\hline Independent variable & $\begin{array}{l}\text { Random } \\
\text { effects } \\
t \in\{1, . ., 10\}\end{array}$ & $\begin{array}{c}\text { Arellano- } \\
\text { Bond } \\
t \in\{2, . ., 10\}\end{array}$ \\
\hline Constant & $23.886^{* * * *}$ & $-1.29^{* *}$ \\
& $(2.730)$ & $(0.205)$ \\
$L_{i}$ & $13.504^{* * *}$ & $($ dropped $)$ \\
& $(3.113)$ & \\
Round & $-1.445^{* * *}$ & \\
$L_{i} \times$ Roun & $(0.293)$ & \\
Lagged own & 0.152 & 0.081 \\
contribution & $(0.334)$ & $(0.054)$ \\
Others' lagged \\
average contribution
\end{tabular}

Note: ${ }^{* * *}$ significant at $1 \% ;{ }^{* *}$ significant at $5 \%$ (std. error in parenthesis)

Treatment dummy $L_{i}=1$ for Leagues treatment; $L_{i}=0$ for VCM

with the average contribution of the others by the generalized method of moments to ensure the consistency of the corresponding panel data structure. In particular we use the Arellano-Bond estimator implemented in the STATA software package. ${ }^{17}$ The results, as reported in the right column of Table 2, support the following observation.

\section{Observation 3}

The dynamics of contributions seem to be treatment-independent. Contributions adjust towards the lagged average-contribution of the others in both treatments.

\section{Support}

The observation shows that the dynamics in the Leagues treatment are similar to the ones in the VCM, but contribution levels are absolutely higher. According to the

\footnotetext{
${ }^{17}$ A similar approach was used in Neugebauer et al. (2009). In particular, we use here the one-step least squares approach which employs the lagged variables as instruments (Arellano and Bond 1991). The $p$ values of the Sargan test of over-identifying restrictions and the $m_{1}$ and $m_{2}$ statistics are $0.000,0.000$ and 0.516 , respectively. Thus the validity of the instruments and the absence of misspecified dynamic structures are verified.
} 
random-effects regression-result reported in the left column of Table 2, this difference in contribution levels seems to be unchanging across rounds. Given the fact that within our theoretical framework only the beliefs about the continuation payoffs change when moving from the VCM to the Leagues treatment, these observed constantly higher contribution levels might indicate that subjects' beliefs about the continuation-payoff differential may also have been unchanging during the experiment. Actually one could find evidence for this indication if one considers the differences in round-ahead contributions during the experiment. Thus, the assumption of myopic behavior in the experiment seems not too far-fetched.

\section{Induced-beliefs effect}

Hypothesis 2 is based on the idea that the difference in subjects' beliefs about their continuation payoff is a main driver of the treatment effect. In relation to this idea, our Leagues treatment may be challenged in the following two respects. First, one possible argument is that these beliefs are strongly induced by the procedure of initially forming the high and low contribution groups. If beliefs drive the positive effect of promotion, altering this procedure should significantly change its effectiveness. Secondly, the limited feedback makes updating of individual beliefs on the continuationpayoff differential rather difficult. A natural benchmark is to give participants full information.

Control treatments and hypotheses We address these two issues in two control treatments, which are identical to the Leagues' treatment up to the following ceterisparibus changes.

(a) The Random Position treatment arbitrarily assigns to one group, ceteris paribus, the major league position "Group 1" in the first round. No positive continuationpayoff differential can initially be expected in this treatment.

(b) The Information treatment reveals the contributions to the minor and Major league to each subject after each round. Given this information, time-consistent beliefs justify zero contributions, i.e., equilibrium-beliefs that lack sequential rationality are difficult to defend. However, as an adaptation of beliefs to feedback is likely to occur, we may expect in line with the adaptive conditional-cooperation conjecture (Neugebauer et al. 2009) that the contributions positively respond to the past continuation-payoff differential. The following testable hypothesis summarizes our ex-ante expectations.

Hypothesis 3 Induced beliefs may affect the outcome in the Leagues treatment.

(a) The effect of promotion and demotion is dampened in the Random-Position treatment compared to the Leagues treatment. No differences to the VCM are initially expected.

(b) The effect of promotion and demotion may be dampened in the Information treatment. Continuation payoffs may be lower and more volatile than in the Leagues treatment. 
Results Two additional experimental sessions were conducted at LINEEX under identical procedures as described in Sect. 2 subject to the explained ceteris-paribus changes. Thus we gathered 7 independent observations of 8-subjects groups for each the Random-Position treatment and the Information treatment. The average contributions in each treatment are plotted in Fig. 2. The following two observations summarize our results.

\section{Observation 4}

Contribution levels in the Random-Position treatment and in the VCM are not significantly different. In the Leagues treatment, they are significantly larger.

\section{Support}

As indicated in Fig. 2, when group names are randomly assigned in the first round, subjects' contributions are equal to those of the Baseline. Only from round 5 on, and probably because of group-formation ongoing, contributions in the Random-Position treatment are slightly higher than in the VCM although not statistically different. According to the two-tailed Mann-Whitney test, the null hypothesis of no differences in contributions cannot be rejected in any round at the $10 \%$ level of significance. According to the one-tailed Mann-Whitney test, on the other hand, we reject the null hypothesis of no differences between the average contributions in the Leagues treatment and the Random-Position treatment. Overall $(p=.001)$ and in each but the last round $(p=.101)$, contributions are significantly larger in the Leagues treatment than in the Random-Position treatment.

\section{Observation 5}

Contribution levels in the Information treatment are smaller than in the Leagues treatment in the first two rounds but not significantly different overall. Estimated continuation-payoff differentials are smaller and more volatile than in the Leagues treatment.

\section{Support}

Contributions for the first two rounds are significantly lower than in the Information treatment (one-tailed Mann-Whitney test $p \leq 0.022$ ). ${ }^{18}$ The differences are not significant overall ( $p=.115)$ and in any of the later rounds. Figure 2 reveals that up to round 7 contributions show an upward slope implying that contributions in the Information treatment end-up higher than those of the VCM and equal to those of the Leagues treatment. For the Leagues, the Information and the Random-Position treatments we estimate continuation-payoff differentials of 30.0, 22.9 and 27.6 respectively. The differences to the Leagues treatment are significant for the Information treatment (one-tailed Mann-Whitney test, $p=.003$ ), and for the RandomPosition treatment (two-tailed Mann-Whitney test, $p=.070$ ). The average percentage standard-deviations for the estimated nine-round continuation-payoff differentials are $0.206,0.387$, and 0.278 for these treatments, respectively. Compared to the

\footnotetext{
${ }^{18}$ Initial contributions are not significantly different to those of the VCM (one-tailed Mann-Whitney test, $p=0.183)$.
} 
Leagues treatment, thus, the Information treatment has a significantly higher volatility (one-tailed Mann-Whitney test, $p=0.009$ ), but the differences to the RandomPosition treatment are not significant (two-tailed Mann-Whitney test, $p=0.364$ ). The relatively high volatility of the continuation-payoff differential in the Information treatment indicates again the adaptive nature of the contribution dynamics; if the differential is large [small] in one period, high incentives for promotion [demotion] lead to a reduced [increased] continuation-payoff differential in the following period.

\section{Concluding remarks}

In this paper we have discussed how our promotion-demotion mechanism with two equally-sized but vertically segregated groups (the "Major league" and the "minor league") may affect voluntary contributions and regrouping in the experiment. We found that contribution levels in the Leagues treatment represent an increase of about $90 \%$ relative to the VCM. We also reported that deliberate group-formation was enabled since more cooperative subjects more frequently affiliated with the Major league. The potential of exploitation by free-riding was thus reduced similarly to a "law of one price", i.e., free-riders could not increase their payoffs by chasing the more cooperative subjects in the Major league (as in Erhard and Keser 1999).

Based on our theoretical discussion we anticipated increased contribution levels between the VCM and the Leagues treatment as we argued that higher equilibriumlevels arise if beliefs lack sequential rationality. In line with this conjecture we also found contributions were not significantly different to the VCM when Major and minor leagues were chosen at random, i.e. the Random-Position treatment. When information about continuation-payoff differentials makes beliefs converge as in the Information treatment, contributions and continuation payoffs initially exhibit a significant effect when compared to the Leagues treatment. Given these differences, our study provides some experimental evidence that beliefs can be non-sequentially rational. The convergence of average contributions in the Information and Leagues treatments, nevertheless, shows that regrouping induces incentives for promotion even in the absence of non-perfect equilibria. ${ }^{19}$ Consequently, our theoretical model does not give a full account of the behavior in our experiment. A more general model would have to take account of the fact that people are heterogeneous with regards to their willingness-to-cooperate and their beliefs about others as suggested by Page et al. (2005). The development of such a more general theory of group formation, however, is beyond the scope of our project.

\section{References}

Ahn, T. K., Ostrom, E., \& Walker, J. (2003). Heterogeneous preferences and collective action. Public Choice, 117, 295-314.

\footnotetext{
${ }^{19}$ The non-declining pattern of contributions in the Random-Position treatment reflects the fact that the more cooperative subjects move to the Major league also in the two control treatments.
} 
Ahn, T. K., Isaac, M., \& Salmon, T. C. (2008). Endogenous group formation. Journal of Public Economic Theory, 10(2), 171-194.

Ahn, T. K., Isaac, M., \& Salmon, T. C. (2009). Coming and going: experiments on endogenous group sizes for excludable public goods. Journal of Public Economics, 93(1-2), 336-351.

Arellano, M., \& Bond, S. (1991). Some tests of specification for panel data: Monte Carlo evidence \& an application to employment equations. The Review of Economic Studies, 58, 277-297.

Belzil, C., \& Bognanno, M. (2008). Promotions, demotions, halo effects and earnings dynamics of American executives. Journal of Labor Economics, 26(2), 287-310.

Brandts, J., \& Schram, A. (2001). Cooperation and noise in public goods experiments: applying the contribution function approach. Journal of Public Economics, 79(2), 399-427.

Burlando, R. M., \& Guala, F. (2005). Heterogeneous agents in public goods experiments. Experimental Economics, 8, 35-54.

Charness, G., Cobo-Reyes, R., \& Jiménez, N. (2011). Efficiency, team building, and identity in a publicgoods game. Working paper, Dept. of Economics, University of California Santa Barbara.

Charness, G., \& Yang, C.-L. (2010). Public goods provision with voting for exclusion, exit, and mergers: an experiment. Working paper, Dept. of Economics, University of California Santa Barbara.

Coricelli, G., Fehr, D., \& Fellner, G. (2004). Partner selection in public goods experiments. The Journal of Conflict Resolution, 48(3), 356-378.

Croson, R. T. A. (2007). Theories of commitment, altruism and reciprocity: evidence from linear public goods games. Economic Inquiry, 45(2), 199-216.

Davis, D., \& Holt, C. A. (1993). Experimental economics. Princeton: Princeton University Press.

Erhard, K.-M., \& Keser, C. (1999). Mobility and cooperation: on the run. Scientific series. Montreal: CIRANO.

Fischbacher, U. (2007). z-tree-Zurich toolbox for readymade economic experiments. Experimental Economics, 10, 171-178.

Fischbacher, U., \& Gächter, S. (2010). Social preferences, beliefs, and the dynamics of free riding in public goods experiments. American Economic Review, 100(1), 541-556.

Fischbacher, U., Gächter, S., \& Fehr, E. (2001). Are people conditionally cooperative? Evidence from a public goods experiment. Economics Letters, 71(3), 397-404.

Gächter, S., \& Thöni, C. (2005). Social learning and voluntary cooperation among like-minded people. Journal of the European Economic Association, 3(2-3), 303-314.

Gunnthorsdottir, A., Houser, D., McCabe, K., \& Ameden, H. (2007). Dispositions, history and contributions in public goods experiments. Journal of Economic Behavior \& Organization, 62, 304-315.

Gunnthorsdottir, A., Vragov, R., Seifert, S., \& McCabe, K. (2010a). Near-efficient equilibria in contribution-based competitive grouping. Journal of Public Economics, 94(11-12), 987-994.

Gunnthorsdottir, A., Vragov, R., \& Shen, J. (2010b). Tacit coordination in contribution-based grouping with two endowment levels. Research in Experimental Economics, 13, 13-75.

Hey, J. D. (1991). Experiments in economics (uncertainty and expectations in economics). Oxford: Blackwell.

Keser, C. (2002). Cooperation in public goods experiments. In F. Bolle \& M. Lehmann-Waffenschmidt (Eds.), Surveys in experimental economics, Heidelberg: Physica-Verlag.

Keser, C., \& van Winden, F. (2000). Conditional cooperation and voluntary contributions to public goods. Scandinavian Journal of Economics, 102, 23-39.

Kräkel, M. (2006). Splitting leagues. Journal of Economics, 88(1), 21-48.

Lazear, E. (1992). The job as a concept. In W. J. Bruns Jr. (Ed.), Performance measurement, evaluation, and incentives, Boston: Harvard Business School Press.

Ledyard, J. O. (1995). Public goods: a survey of experimental research. In J. Kagel \& A. Roth (Eds.), The handbook of experimental economics, Princeton: Princeton University Press.

Levati, M. V., \& Neugebauer, T. (2004). An application of the English clock market mechanism to public goods games. Experimental Economics, 7, 153-169.

Nagel, R. (1995). Unraveling in guessing games: an experimental study. American Economic Review, 85, 1313-1326.

Neugebauer, T., Perote, J., Schmidt, U., \& Loos, M. (2009). Selfish-biased conditional cooperation: on the decline of contributions in repeated public goods experiments. Journal of Economic Psychology, 30, 52-60.

Ones, U., \& Putterman, L. (2007). The ecology of collective action: a public goods and sanctions experiment with controlled group formation. Journal of Economic Behavior \& Organization, 62(4), 495-521.

Page, T., Putterman, L., \& Unel, B. (2005). Voluntary association in public goods experiments: reciprocity, mimiery and efficiency. Economic Journal, 115, 1032-1053. 